\title{
Environmental predictors of livestock predation: a lion's tale
}

\author{
J. A. D. Robertson, M. Roodbol, M. D. Bowles, S. G. Dures and J. M. Rowcliffe
}

Abstract Negative interactions between people and large carnivores are common and will probably increase as the human population and livestock production continue to expand. Livestock predation by wild carnivores can significantly affect the livelihoods of farmers, resulting in retaliatory killings and subsequent conflicts between local communities and conservationists. A better understanding of livestock predation patterns could help guide measures to improve both human relationships and coexistence with carnivores. Environmental variables can influence the intensity of livestock predation, are relatively easy to monitor, and could potentially provide a useful predictive framework for targeting mitigation. We chose lion predation of livestock as a model to test whether variations in environmental conditions trigger changes in predation. Analysing 6 years of incident reports for Pandamatenga village in Botswana, an area of high human-lion conflict, we used generalized linear models to show that significantly more attacks coincided with lower moonlight levels and temperatures, and attack severity increased significantly with extreme minimum temperatures. Furthermore, we found a delayed effect of rainfall: lower rainfall was followed by a significantly increased severity of attacks in the following month. Our results suggest that preventative measures, such as introducing deterrents or changing livestock management, could be implemented adaptively based on environmental conditions. This could be a starting point for investigating similar effects in other large carnivores, to reduce livestock attacks and work towards wider human-wildlife coexistence.

Keywords Carnivores, human-wildlife conflict, lion, livestock predation, moon, Panthera leo, rainfall, temperature

Supplementary material for this article is available at https://doi.org/10.1017/So030605318001217

J. A. D. Robertson (Corresponding author) Silwood Park Campus, Imperial College London, London, UK. E-mail joshrobertsoniwb@gmail.com

M. Roodbol and M. Bowles Walking for Lions, Pandamatenga, Botswana

S. G. Dures and J. M. Rowcliffe Institute of Zoology, Zoological Society of London, London, UK

Received 6 April 2018. Revision requested 9 August 2018.

Accepted 12 September 2018. First published online 7 June 2019.

\section{Introduction}

T uman-wildlife interactions vary in frequency, inten1 sity, and on a continuum from positive to negative (Soulsbury \& White, 2015). Negative interactions can pose significant threats to human welfare and livelihoods, and to ecosystem structure and function (Estes et al., 2012; Kansky et al., 2014). They are often complex, encompassing an array of species and situations, each with unique factors and thus potential solutions (Dickman, 2010). Conflicts resulting from negative human-wildlife interactions are likely to be exacerbated in the future with further growth of the human population and ongoing destruction of habitats for wildlife.

Large carnivores can cause substantial direct and indirect costs to humans and are particularly prevalent in adverse human-wildlife interactions because they often predate livestock and have large home ranges that are likely to overlap with human-dominated areas (Macdonald \& Sillero-Zubiri, 2002; Inskip \& Zimmermann, 2009). Conserving large carnivores is vital because they are keystone species that act as umbrella and flagship species for wider biodiversity protection (Loveridge et al., 2009; Macdonald \& Loveridge, 2010), and many are deeply intertwined with human cultures (Kellert et al., 1996). However, most (77\%) of the largest carnivores now have decreasing populations (Ripple et al., 2014). For example, although negative interactions between humans and African lions Panthera leo have happened for millennia (Loveridge et al., 2007), the lion population (43\%) and range (92\%) have declined dramatically in recent decades (Bauer et al., 2015). Habitat destruction and land-use changes, resulting from the cessation of traditional sustainable land-use practices following European colonization of African countries, are primarily responsible for these declines (Clover \& Eriksen, 2009; Bauer et al., 2015). As a consequence of their now restricted range and diminished population, the future survival of the African lion may depend upon coexistence with farmers in human-dominated landscapes, because the effectiveness of protected areas can be compromised when lions are drawn out of these areas to replace those killed on the borders (Loveridge et al., 2007; Macdonald \& Loveridge, 2010).

Negative human-carnivore interactions will probably escalate in the future as global livestock production is projected to rise from $258 \mathrm{Mt}$ in 2005-2007 to $455 \mathrm{Mt}$ in 2050, with much of this growth occurring in developing countries (Alexandratos \& Bruinsma, 2012). This is a complex issue (Dickman, 2010; Madden \& McQuinn, 2014), with both 
tangible and intangible costs to human communities and carnivores (Redpath et al., 2015a; Dickman \& Hazzah, 2016; Kansky et al., 2016). In particular, the economic costs of predation for livestock farmers are significant (Butler, 2000; Patterson et al., 2004) and can lead to substantial losses of annual household income (Wang \& Macdonald, 2006). Consequently, retaliatory killings are common and lead to conflicts between conservationists and livestock farmers (Redpath et al., 2015b).

Examining the factors that affect livestock predation can help us understand patterns and subsequently guide measures to reduce attacks, foster relationships between conservationists and farmers, and work towards coexistence of farmers and predators (Carvalho et al., 2015). Livestock predation risk is influenced by multiple variables, including livestock abundance, farming techniques, mitigation measures, presence of trophy hunting, changes in laws and their implementation, proximity to human settlements and protected areas (Yu et al., 2006; Van Bommel et al., 2007), natural prey density and environmental conditions (Sunquist \& Sunquist, 1989; Polisar et al., 2003; Azevedo \& Murray, 2007; Tortato et al., 2015). Environmental conditions such as temperature, light level and rainfall are relatively easy to monitor and have overarching impacts on livestock predation by carnivores. It is plausible that variations in such factors could trigger changes in predation patterns, and could thus be used as predictors of the likelihood of attacks. We chose livestock predation by lions as a model interaction to test this idea.

Environmental conditions, particularly temperature and rainfall, have significant effects on lion biology and demography (Celesia et al., 2010). Rainfall has been associated with both increases (Patterson et al., 2004; Kuiper et al., 2015) and decreases in lion attacks on livestock (Butler, 2000; Schiess-Meier et al., 2007), which are typically related to prey abundance. Compared to non-protected landscapes, protected areas usually have higher prey levels that remain relatively constant over time in non-migratory systems (Macdonald \& Loveridge, 2010). This suggests rainfall is less likely to influence rates of livestock predation in regions surrounded by protected areas. Although temperature is thought to have no influence on lion predation of livestock (Patterson et al., 2004), lions are more active during colder periods and more nocturnal in areas with higher mean annual temperatures (Hayward \& Slotow, 2009); temperature also affects food intake by lions (West \& Packer, 2002). Because hunting for prey increases body temperature in lions, and their biology leaves them vulnerable to overheating, we expected livestock predation levels to reflect their preference for lower external temperatures. Lions prefer periods without moonlight for hunting wild prey (Schaller, 1972), and travel closer to livestock at lower moonlight levels (Oriol-Cotterill et al., 2015), probably because of the reduced risk of being seen by people and prey.
We investigated how temperature, moon phase and rainfall affected the incidence and severity of lion predation of livestock over a 7-year period in an area with frequent negative human-lion interactions. We hypothesized that (1) livestock predation would increase with decreasing temperature, (2) livestock predation would increase with decreasing moonlight levels, and (3) rainfall would have no significant effect on livestock predation, given that the study area is surrounded by protected areas.

\section{Study area}

The study area (Fig. 1) covers c. 4,500 $\mathrm{km}^{2}$ around Pandamatenga village in north-east Botswana, in the Chobe district near the border with Zimbabwe and close to Hwange National Park. Pandamatenga's human population increased from 1,369 in 2007 (African Development Bank, 2008) to c. 1,943 in 2011 (Central Statistics Office of Botswana, 2015). It is one of Botswana's least arid areas, with a mean annual rainfall of $600 \mathrm{~mm}$, almost all of which occurs during October-April, with a peak during December-February (African Development Bank, 2008).

Pandamatenga is situated between several protected areas that support c. 5 lion prides comprising at least 52 individuals. Farms are small subsistence operations and all livestock are kept in protective enclosures (kraals) at night and released for grazing during the day; the robustness of the kraals, presence of any other mitigation methods and grazing regimes differ between farmers.

\section{Methods}

\section{Incident reports}

Botswana provides a state-funded compensation scheme in which farmers file a report when they lose livestock to lions (Hemson et al., 2009). The Department of Wildlife and National Parks provided us with reports on incidents that took place during January 2010-April 2016. We believe these reports provide comprehensive coverage of lion-livestock incidents during this period because farmers must file a report to claim compensation for attacks, and farmers in Pandamatenga lack the financial capacity to leave these unreported. The data included reports on 395 incidents, each with information on date, location, source, livestock owner, the species and number of livestock involved, and whether the incident took place inside or outside a kraal.

\section{Data preparation}

Three response variables were explored: incident occurrence (a measure of attack likelihood), the number of livestock involved in incidents (a measure of attack severity), and the total cost of incidents (an alternative measure of attack 


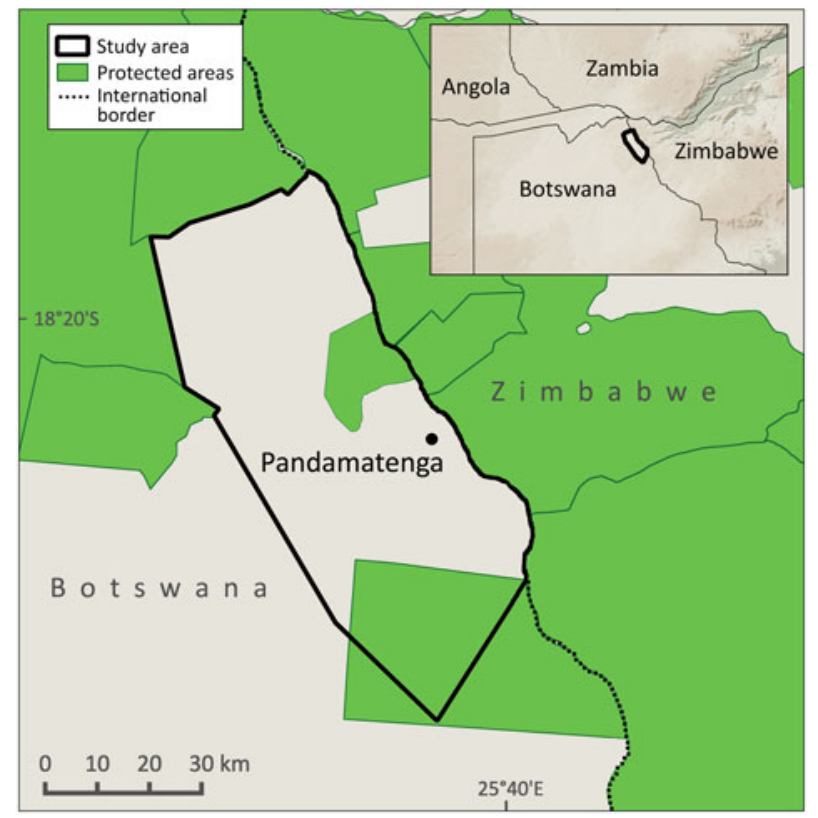

FIG. 1 The study site around Pandamatenga village in northeast Botswana, showing the area from which the analysed incident reports on livestock predation by lions Panthera leo originated.

severity, reflecting farmers' likely perception of the events). All three response variables were expressed on a daily, monthly, and annual scale. We used a daily scale to investigate the effect of temperature and moon phase on response variables. Daily data covered each day during 1 January 2010-30 April 2016, and included incidents, non-incidents, and the associated response and environmental variables; we removed values of zero for the analysis of livestock attacked per incident and associated cost. We used a monthly scale to investigate the immediate and delayed effect of temperature and rainfall on monthly totals of response variables during January 2010-April 2016. We used an annual scale to examine large-scale patterns in response variables during 2010-2015; data from 2016 were removed from the annual analysis because they were only available until April that year.

Monetary cost in Botswana Pula (BWP) was assigned to each incident based on current compensation scheme values; as of 2013 these were set in BWP as 450 for a goat, 1,000 for a calf, 1,100 for a pig, 3,00o for a heifer, cow, bullock, or oxen, and 5,500 for a bull. Costs were assigned to the incidents irrespective of whether an animal was killed or injured, because information on the severity of the injuries or any livestock fatalities was not included in the reports. Five reported incidents concerned lions being translocated from farmers' lands; these were removed because they did not involve attacks on livestock. Incidents involving dogs $(\mathrm{n}=3)$ and chickens $(n=1)$ were included as incidents, but not in the number of livestock attacked or the cost of incidents as neither are covered under the compensation scheme: dogs are not livestock, and the single incident involving 23 chickens could have exerted undue leverage on the results.
We accessed monthly rainfall data $(\mathrm{mm})$ from the meteorological office in Pandamatenga for July 2013-March 2016. Daily moon phase data during 1 January 201030 April 2016 were downloaded from USNO (2016). According to results from Packer et al. (2011), three moon phases were defined: the full moon and subsequent 9 days (phase 1), the 10 days prior to the full moon (phase 2), and the intermediate days when the moon is least visible (phase 3). Moonlight levels are lowest during phase 3 and highest during phases 1 and 2; however, during phase 1 the moon does not rise until after sunset and thus leaves a period of darkness, whereas during phase 2 the moon is above the horizon at sunset and there is no such interlude. We obtained data on temperature for Pandamatenga during 1 January 2010-30 April 2016 from NOAA (2016). This included daily values for minimum and maximum temperature, and monthly values for extreme daily maximum and minimum, monthly mean maximum and minimum, and monthly mean temperatures. We used linear interpolation to fill in 416 minimum and 300 maximum temperature values that were missing from the daily data (of a total of 1,990 values), with average data gaps being 1.8 and 1.3 days, respectively; linear interpolation was deemed to be more accurate than polynomial, based on plots of the data. Monthly temperature and rainfall data were shifted to match the response variables 1 and 2 months ahead, to test for any delayed response; extreme daily temperatures were not used in these models because it is unlikely that an extreme temperature on a single day would affect the incidents in the following months.

\section{Data analysis}

We used $R$ 3.X for all data analysis (R Development Core Team, 2015). To test our hypotheses and investigate the effect of environmental variables on response variables, we used generalized linear models and assumed the following error distributions: binomial for the occurrence of an incident, Poisson for the number of incidents, livestock attacked per month and livestock attacked per incident, and Gaussian for cost (log) per incident and month. We used generalized linear models for daily data to assess the effect of temperature and moon phase on response variables, on monthly data to assess the effect of temperature and rainfall, and on shifted monthly data to assess delayed effects of temperature and rainfall. To control for interdependence between variables, we excluded variables correlated by $r>0.85$. When our models assuming Poisson error distributions showed a residual deviance higher than residual degrees of freedom, we compensated for this overdispersion by assuming quasi-Poisson errors. We followed a step-by-step procedure to find the model with the best fit based on Akaike's information criterion (AIC) and the residual deviance relative to degrees of freedom. 
TABLE 1 Summary of the best fit generalized linear models examining the effect of moon phase and temperature on incidents of lion Panthera leo predation on livestock and their severity in Pandamatenga. Significant effects are indicated with *

\begin{tabular}{llllll}
\hline Response variable (error distribution) & Environmental variable & Coefficient estimate $^{1}$ & SE & P & Residual deviance (df) \\
\hline Incident (Binomial) & Intercept & -1.195 & 0.190 & $<0.001^{*}$ & $2,099.2(2353)$ \\
& Moon phase 2 & -0.278 & 0.140 & $0.050^{*}$ & \\
& Moon phase 3 & 0.147 & 0.130 & 0.262 & \\
& TMin & -0.026 & 0.011 & $0.017^{\star}$ & \\
Livestock attacked (Poisson) & Intercept & 0.713 & 0.140 & $<0.001^{*}$ & $280.0(374)$ \\
& Moon phase 2 & -0.040 & 0.110 & 0.711 & \\
Cost (log) (Gaussian) & Moon phase 3 & -0.032 & 0.096 & 0.740 & \\
& TMin & -0.017 & 0.008 & $0.032^{*}$ & \\
& Intercept & 7.923 & 0.160 & $<0.001^{*}$ & $300.7(375)$ \\
& Moon phase 2 & -0.067 & 0.120 & 0.575 & \\
& Moon phase 3 & -0.076 & 0.100 & 0.476 & 0.382 \\
\hline
\end{tabular}

${ }^{1} \mathrm{TMin}$, minimum temperature $\left({ }^{\circ} \mathrm{C}\right)$ on a given day.

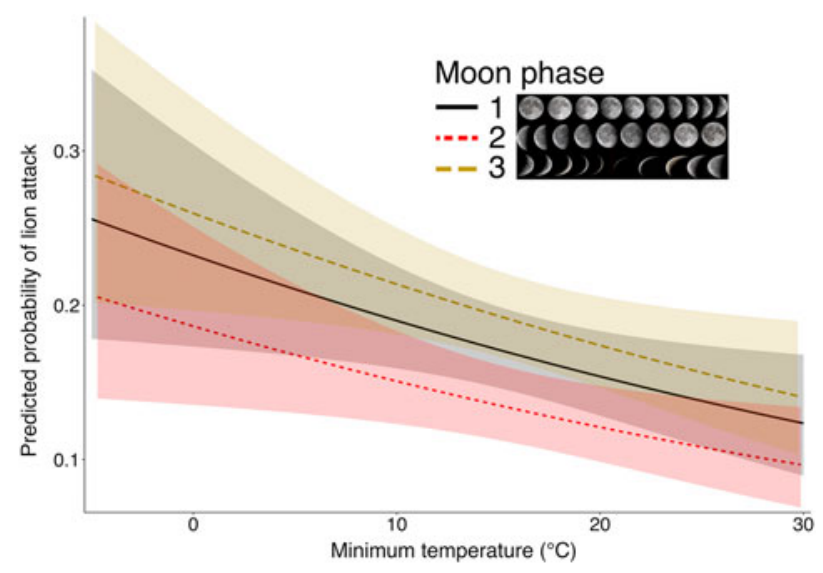

FIG. 2 The predicted probability of a lion attack on livestock in Pandamatenga based on the minimum temperature $\left({ }^{\circ} \mathrm{C}\right)$ of a given day under different moon phases: phase 1 is the full moon and subsequent 9 days, phase 2 is the 10 days prior to the full moon, and phase 3 includes the remaining days around the new moon.

Because we split moon phase into three categories, we used a general linear hypothesis test to assess differences amongst them. We calculated the predicted daily probability of an attack on the back-transformed response scale, for a sequence of temperatures at each moon phase, and plotted responses with $95 \%$ confidence intervals; we extended the minimum temperature range to $-5-30{ }^{\circ} \mathrm{C}$ (from $-1.11-21.56{ }^{\circ} \mathrm{C}$ ), and maximum temperature range to $15-50{ }^{\circ} \mathrm{C}$ (from $20.56-42.22{ }^{\circ} \mathrm{C}$ ) to investigate how potential future changes in extreme temperatures might affect livestock predation.

We used a Kruskal-Wallis $\mathrm{H}$ test to assess differences in the number of livestock involved and cost of incidents between the years based on a per incident basis and on monthly summaries. Seasons were defined as dry (May-October) and wet (November-April). We compared monthly sums of attacks inside and outside kraals and between seasons for all response variables using a Welch two-sample $t$ test and visualized them with box plots.

\section{Results}

Over the 7 years of the study there were 395 lion attacks involving 589 livestock at a total cost of BWP $1,429,850$ (GBP 106,833; Supplementary Table 1).

\section{Temperature and moon phase}

We could not use minimum and maximum temperature in the same generalized linear model because of intercorrelation, and minimum temperature produced the best-fit model for each response variable. Our best-fit generalized linear models (Table 1) showed that the incidence of attacks on livestock and the number of livestock attacked per event both increased with decreasing minimum temperature (Fig. 2). We also found this pattern for maximum temperature, although the effect was weaker (Supplementary Fig. 1). Based on the coefficient for minimum temperature, holding moon phases at a fixed value, there was a $2.52 \%$ increase in the odds of an incident with every $1{ }^{\circ} \mathrm{C}$ decrease. Incidents were more likely to occur in moon phases 3 (around new moon) and 1 (post-full moon) compared to moon phase 2 (pre-full moon); however, there were no differences between moon phases for either the number of livestock attacked per incident or associated cost. Odds ratios showed that the likelihood of an incident occurring during moon phases 1 and 3 was 1.32 and 1.53 times higher, respectively, than during phase 2 (Supplementary Table 2). No environmental variables were significant predictors of cost. These results support our hypotheses 1 and 2 that livestock predation would increase with decreasing temperature and moonlight.

\section{Temperature and rainfall}

All monthly temperature variables were correlated and we selected only the temperature variable that produced the 
TABLE 2 Summary of the best-fit generalized linear models examining the effect of monthly rainfall and temperature on lion-livestock incidents and their severity in Pandamatenga. Significant effects are indicated with *.

\begin{tabular}{llclcc}
\hline Response variable (error distribution) & Environmental variable & Coefficient estimate $^{1}$ & SE & P & Residual deviance (df) \\
\hline Incidents (Quasi-Poisson) & Intercept & 2.456 & 0.470 & $<0.001^{*}$ & $84.2(30)$ \\
& MMeanMin & -0.070 & 0.035 & 0.058 & \\
& Rainfall & 0.003 & 0.003 & 0.239 & \\
Livestock attacked (Quasi-Poisson) & Intercept & 2.894 & 0.270 & $<0.001^{\star}$ & $122.2(30)$ \\
& ExMinTemp & -0.103 & 0.033 & $0.004^{*}$ & \\
Cost (log) (Gaussian) & Rainfall & 0.004 & 0.003 & 0.205 & \\
& Intercept & 9.883 & 2.020 & $<0.001^{*}$ & $244.6(30)$ \\
& MMeanMin & -0.039 & 0.140 & 0.783 & \\
\hline
\end{tabular}

${ }^{1}$ MMeanMin, monthly mean minimum temperature $\left({ }^{\circ} \mathrm{C}\right)$; ExMinTemp, extreme minimum daily temperature $\left({ }^{\circ} \mathrm{C}\right)$.

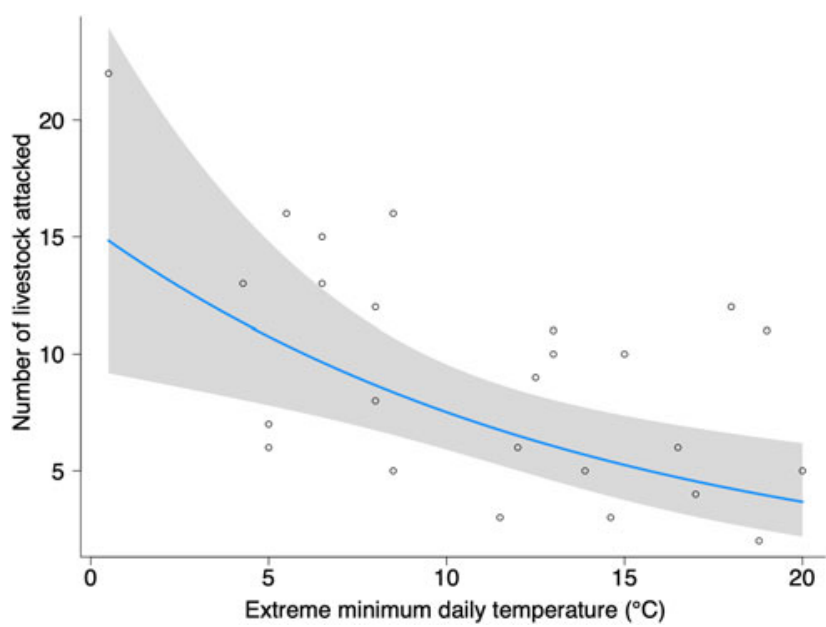

FIG. 3 The effect of extreme minimum daily temperature $\left({ }^{\circ} \mathrm{C}\right)$ on the number of livestock attacked by lions in Pandamatenga per month, showing the fitted generalized linear model and Wald $95 \%$ confidence intervals based on standard errors.

best fit for each model (Table 2). The monthly number of livestock attacked increased significantly with decreasing extreme minimum temperature (Fig. 3), and marginally with decreasing extreme maximum daily temperature (Supplementary Fig. 2); this result again supports our hypothesis 2 that decreasing temperature would increase livestock predation. Although decreasing monthly mean minimum temperatures increased the number of incidents and associated costs, these effects were not significant. Rainfall was not predictive of any response variable, which supports our hypothesis 3 that rainfall has no effect on livestock predation in locations surrounded by protected areas.

\section{Delayed effects of temperature and rainfall}

Temperature had no significant 1-month delayed effect on response variables, nor 2-month delayed effect on incidents or cost (Table 3). However, the number of livestock attacked was negatively associated with mean monthly maximum temperature 2 months earlier (Supplementary Fig. 3). Contrary to our hypothesis 3 that rainfall would not influence attacks in the context of nearby protected areas, we found high levels of rainfall decreased the number of livestock attacked and the associated cost in the following month (Fig. 4). Rainfall had no significant 2-month lag effect on response variables.

\section{Temporal patterns and the effectiveness of kraals}

Attacks on livestock tended to be more frequent and severe in the dry season (Supplementary Fig. 4). However, a KruskalWallis $\mathrm{H}$ test showed there was no significant difference between months in the number of incidents $\left(\chi^{2}(11)=11.827\right.$, $\mathrm{P}=0.377)$, livestock attacked $\left(\chi^{2}(11)=12.647, \mathrm{P}=0.317\right)$ or cost $\left(\chi^{2}(11)=7.615, P=0.747\right)$. Similarly, a Kruskal-Wallis $\mathrm{H}$ test showed there was no significant difference between years in the number of incidents $\left(\chi^{2}(5)=8.936\right.$, $\mathrm{P}=0.112)$, livestock attacked $\left(\chi^{2}(5)=10.251, \mathrm{P}=0.068\right)$, or $\operatorname{cost}\left(\chi^{2}(5)=10.501, \mathrm{P}=0.062\right)$. A Welch two-sample $t$ test showed that significantly more incidents $(t=-4.73$, $\mathrm{df}=119.27, \quad \mathrm{P}<0.00001), \quad$ involving more livestock $(t=-3.149, \mathrm{df}=135.7, \mathrm{P}<0.005)$, at a higher cost $(t=-4.40$, $\mathrm{df}=126.08, \mathrm{P}<0.0001)$, occurred outside kraals, based on monthly summaries (Supplementary Fig. 5).

\section{Discussion}

Although temperature and moon phase are known to affect lion activity (Hayward \& Slotow, 2009; Celesia et al., 2010; Packer et al., 2011; Oriol-Cotterill et al., 2015), our study is the first to show these variables have a significant effect on the occurrence and severity of lion attacks on livestock.

\section{Effects of temperature}

Our hypothesis that livestock predation would increase with decreasing temperature was supported by all models. There 
TABLE 3 Summary of the best-fit generalized linear models examining the delayed effect of temperature and rainfall on lion-livestock incidents and their severity in Pandamatenga. Significant effects are indicated with *.

\begin{tabular}{|c|c|c|c|c|c|c|}
\hline $\begin{array}{l}\text { Response variable } \\
\text { (error distribution) }\end{array}$ & Delay (months) & $\begin{array}{l}\text { Environmental } \\
\text { variable }^{1}\end{array}$ & $\begin{array}{l}\text { Coefficient } \\
\text { estimate }\end{array}$ & SE & $\mathrm{P}$ & $\begin{array}{l}\text { Residual } \\
\text { deviance (df) }\end{array}$ \\
\hline \multirow[t]{6}{*}{ Incidents (Quasi-Poisson) } & \multirow[t]{3}{*}{1} & Intercept & 3.595 & 1.410 & $0.017^{\star}$ & \multirow[t]{3}{*}{$82.73(30)$} \\
\hline & & MeanMaxTemp & -0.064 & 0.047 & 0.179 & \\
\hline & & Rainfall & -0.001 & 0.002 & 0.597 & \\
\hline & \multirow[t]{3}{*}{2} & Intercept & 1.103 & 0.550 & 0.053 & \multirow[t]{3}{*}{$87.70(29)$} \\
\hline & & MeanMinTemp & 0.034 & 0.370 & 0.366 & \\
\hline & & Rainfall & -0.002 & 0.003 & 0.437 & \\
\hline \multirow[t]{6}{*}{ Livestock attacked (Quasi-Poisson) } & \multirow[t]{3}{*}{1} & Intercept & 4.688 & 1.260 & $<0.001^{\star}$ & \multirow[t]{3}{*}{$113.48(30)$} \\
\hline & & MeanMaxTemp & -0.081 & 0.042 & $0.062^{\star}$ & \\
\hline & & Rainfall & -0.005 & 0.002 & $0.047^{\star}$ & \\
\hline & \multirow[t]{3}{*}{2} & Intercept & 5.585 & 1.450 & $<0.001^{\star}$ & \multirow[t]{3}{*}{$128.24(29)$} \\
\hline & & MeanMaxTemp & -0.117 & 0.049 & $0.023^{\star}$ & \\
\hline & & Rainfall & 0.0003 & 0.002 & 0.886 & \\
\hline \multirow[t]{6}{*}{ Cost (log) (Gaussian) } & \multirow[t]{3}{*}{1} & Intercept & 14.254 & 5.190 & $0.010^{*}$ & \multirow[t]{3}{*}{$225.06(30)$} \\
\hline & & MeanMaxTemp & -0.152 & 0.167 & 0.368 & \\
\hline & & Rainfall & -0.018 & 0.007 & $0.024^{\star}$ & \\
\hline & \multirow[t]{3}{*}{2} & Intercept & 19.942 & 5.580 & $0.001^{*}$ & \multirow[t]{3}{*}{$245.50(29)$} \\
\hline & & MeanMaxTemp & -0.365 & 0.179 & 0.051 & \\
\hline & & Rainfall & 0.001 & 0.008 & 0.870 & \\
\hline
\end{tabular}

${ }^{1}$ MeanMaxTemp, mean monthly maximum temperature $\left({ }^{\circ} \mathrm{C}\right)$; MeanMinTemp, mean monthly minimum temperature $\left({ }^{\circ} \mathrm{C}\right)$.

have been few previous studies on the effect of temperature on livestock predation by carnivores. Patterson et al. (2004) found no correlation between temperature and the frequency or severity of lion attacks on livestock. However, their analysis only included temperature data for most days during 1 year whereas we were able to analyse 6 years of data.

Livestock predation is affected by husbandry practices, which vary between individuals and on a spatio-temporal scale (Kgathi et al., 2012). For example, some farmers may leave their cattle out for grazing at night during warmer periods, and others may put less effort into preventing livestock attacks during colder periods to avoid uncomfortable conditions, resulting in more incidents. However, we have no data on individual farmers' husbandry strategies to assess this.

We can, however, infer from our results that lion physiology and behaviour influence livestock predation. Lions must maintain their core body temperature at $38-39{ }^{\circ} \mathrm{C}$, but have few behavioural mechanisms to facilitate this at high ambient temperatures (Willmer et al., 2006). Given that a successful livestock hunt increases a lion's body temperature (through locomotion, stress and feeding) and a lion's biology leaves it vulnerable to overheating, it is probable that lions favour lower and avoid higher ambient temperatures for livestock predation. Overheating when hunting is a significant danger for lions because they have large amounts of heat-producing muscle tissue and a low surface area to volume ratio, and because locomotion can increase heat production to $10-15$ times that of the basal metabolic rate (Pough et al., 2012). Overheating is probably a greater problem for males because of their larger body size and the insulating properties of their manes, and males feed significantly less in warmer months, whereas food intake of females remains unchanged at higher temperatures (West \& Packer, 2002). Most lions predating livestock are male, and thus males are probably overrepresented in our data (Macdonald \& Loveridge, 2010). Although hunting livestock may require less physical exertion than hunting wild prey, this could conceivably be outweighed by the fear of human activities in areas with frequent negative humanlion interactions. For example, the body temperature of cheetahs significantly increases after a successful hunt because of the stress induced from remaining vigilant for a dominant predator, rather than the physical exertion of the hunt itself (Hetem et al., 2013). Lions hunting livestock around pastoral lands exhibit a wariness of human activity, altering their behaviour and moving faster than usual (Valeix et al., 2012; Oriol-Cotterill et al., 2015). It is therefore conceivable that lions will be in an alarmed state after a successful livestock hunt, resulting in higher body temperatures and stress hyperthermia (Meyer et al., 2008; Hetem et al., 2013), and thus have a preference for predating livestock during colder periods. Further increasing livestock predation during extremely low temperatures may be a behavioural strategy to avoid critically low body temperatures (Stryker, 2016), as lions require more energy for thermoregulation during these periods, and large meat-based meals increase body temperature significantly (West \& Packer, 2002; Pough et al., 2012).

Rather than temperature having a direct effect on predation, it could be that variations in wild prey abundance 

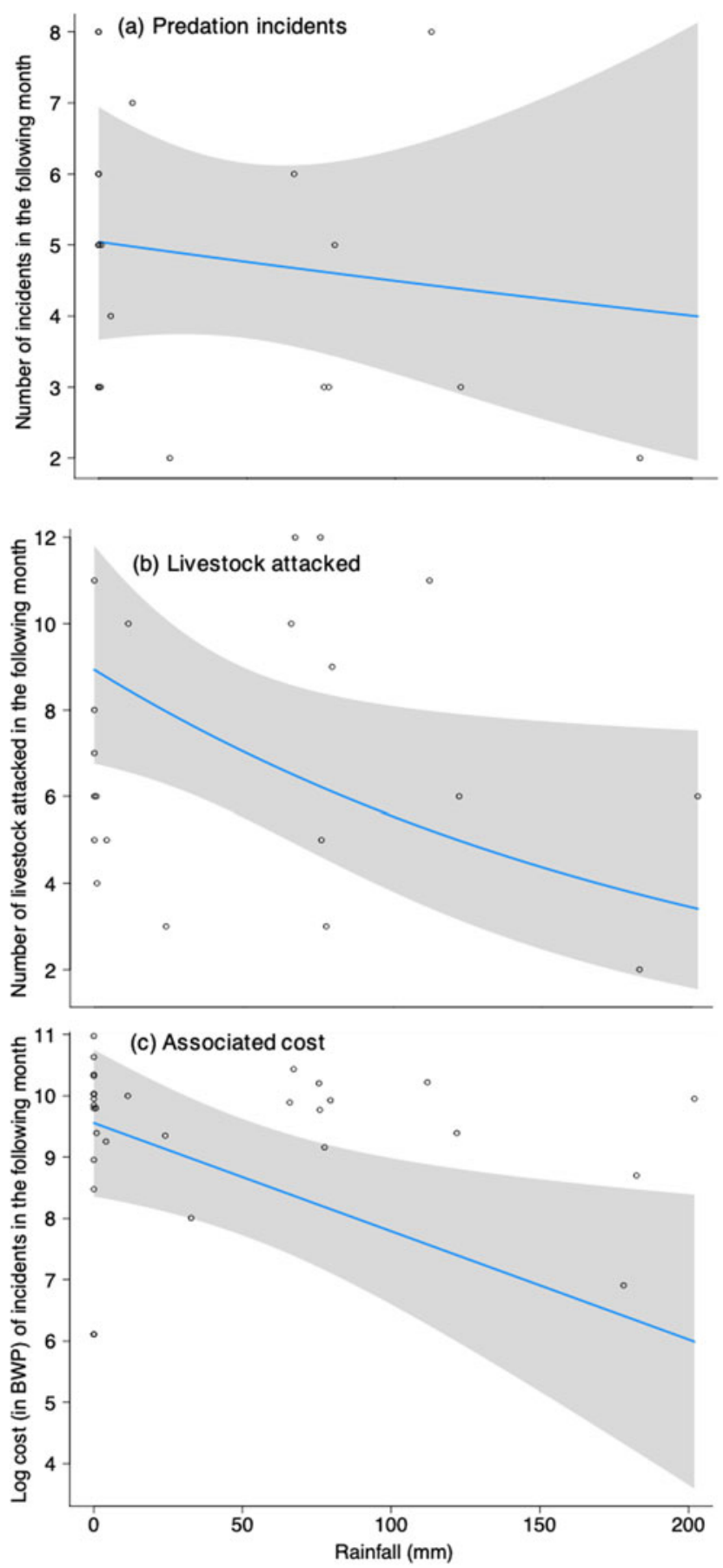

FIG. 4 The effect of the sum of monthly rainfall on (a) the number of predation incidents, (b) the number of livestock attacked, and (c) the log associated cost of attacks in Pandamatenga in the following month, showing the fitted generalized linear model lines and Wald 95\% confidence intervals based on standard errors.

coincide with seasonal temperature changes, as lionlivestock predation is affected by the relative abundance of wild prey compared to livestock (Hemson, 2003). The mass movement of zebras (Naidoo et al., 2014), and potentially other ungulates (Harris et al., 2009), from Chobe river to
Nxai Pan National Park in the wet season may decrease prey availability around Pandamatenga during that time. However, our results show incident number and severity to be generally higher in the dry season, so it is unlikely this migration affects attacks around Pandamatenga. Furthermore, high availability of wild prey has been shown to both increase (Stahl et al., 2001; Treves et al., 2004) and decrease (Hemson, 2003; Valeix et al., 2012) levels of livestock predation; increases in livestock predation may occur because higher wild prey levels can sustain greater predator populations (Macdonald \& Loveridge, 2010).

\section{Effects of moon phase}

Our findings agreed with our hypothesis that livestock predation would increase with decreasing moonlight levels. This is consistent with research indicating that lions travel closer to kraals at lower moonlight levels (Oriol-Cotterill et al., 2015), and that attack rates of lions on people was 2-4 times lower in the 10 days before the full moon compared to the 10 days after, when the moon rises after sunset, resulting in a period of darkness (Packer et al., 2011). Lions move more slowly and their movement paths are more tortuous when moonlight levels are high, indicating more caution (Oriol-Cotterill et al., 2015), and we infer that lions utilize periods of lower moonlight for hunting livestock because it is easier to avoid detection by people and potential prey.

\section{Effects of rainfall}

Rainfall had no immediate effect on the number of incidents or their severity, which supports our hypothesis that livestock predation should be unrelated to rainfall in the context of stable wild prey numbers within nearby protected areas. However, attacks were significantly less severe in the month following increased rainfall, which contradicts this hypothesis. Patterson et al. (2004), in a study carried out in Tsavo National Park, found no delayed relationship between rainfall and predation with lags of 1-6 months but found attacks to be most frequent in the wet season. Pandamatenga's different natural prey densities and landscape could be responsible for this discrepancy between our results and the ones reported from Tsavo National Park. Farmers take their livestock further from kraals when vegetation density and water levels are low (OriolCotterill et al., 2015), leaving a higher number of livestock more vulnerable to predation. Decreasing levels of rainfall will probably lead to lower vegetation density and water availability in the following month, which could explain the delayed relationship between rainfall and attack severity. 


\section{Temporal patterns and the effectiveness of kraals}

The fact that there was no significant seasonal trend in the number or severity of attacks suggests that there was relatively high prey availability throughout the year at Pandamatenga, possibly because regions surrounded by protected areas typically have higher ungulate populations (Macdonald \& Loveridge, 2010). We found significantly more incidents occurred outside kraals, which is consistent with other research (Valeix et al., 2012) and suggests kraals are effective to some extent in reducing attacks.

\section{Limitations, and directions for future research}

Although we have shown that environmental factors could have significant effects on livestock predation, this only facilitates an understanding of one part of a complex system in which other variables, particularly human factors, are equally important (Oriol-Cotterill et al., 2015). Future work should encompass a more holistic analysis of the variables affecting predation, including environmental, human, and spatial factors, to compare the effects of these broad categories on livestock predation by multiple large carnivores in different locations. In addition, it would be of value to investigate the effect of temperature and moon phase specifically on livestock predation by other large carnivores in different ecosystems, to establish whether these variables can act as indicators for guiding mitigation more broadly.

We had no information regarding the time of day of attacks, so although most attacks probably occur at night (Macdonald \& Loveridge, 2010), inferences of high temperature avoidance must be taken as general patterns exhibited by the data rather than actual daily preferences shown by lions. Confidence in our results would be strengthened with data on natural prey density and lion predation levels on natural prey, which will have an impact on livestock predation. Additionally, moon brightness varies with weather conditions, and our analysis did not consider cloud coverage, which is probably higher in the wet season. Future work should incorporate these data and involve an analysis of human activities and known attacks on both livestock and wild prey by focusing on activity patterns of individual lions.

\section{Management implications}

Environmental variables are easy to monitor and can provide practical guidelines for enhancing mitigation, to help reduce attacks from large carnivores and improve farmer-carnivore coexistence. Considering the demonstrated effect of all environmental variables we investigated, we recommend that livestock farmers increase protective measures for their livestock during colder periods, and particularly when moonlight levels are low. Colder periods typically coincide with the dry season in southern Africa. Furthermore, although the effect of rainfall on livestock predation varies in different areas, measures to prevent predator attacks should be increased in months following lower levels of rainfall in locations surrounded by protected areas. Such measures could include improvements in livestock management, such as keeping cattle within kraals whenever possible and being more vigilant with herding and guarding, using various deterrents (e.g. acoustic, visual or chemical), using specialized guard dogs, or local dogs that act as a warning system, and employing human guardians for livestock (Dickman, 2010). Each area will have different potential for successful mitigations and carnivore conservation based on its ecological, sociological, economic and political profile, and the associated human population pressure (Hemson, 2003; Dickman et al., 2015). Decreasing predator attacks on livestock could help reduce the persecution of large carnivores and maintain the essential ecosystem services they provide, whilst improving relationships between conservationists and farmers, and facilitating human-carnivore coexistence.

Acknowledgements JADR thanks Jocelyne Sze Shimin, George Powell and James Foley for their advice on statistical analyses; Joseph Shepherdson, Jim Humphries, James Adams, Jess Williams and Jacky Morrison for reviewing early drafts; and Hil and Jamie Robertson for their support. All authors thank the Department of Wildlife and National Parks for providing the incident reports that made this project possible.

Author contributions Project conception and study design: JADR, JMR, MR, SGD; writing: JADR; guidance on writing: JMR, SGD; information on local governance, farming practices and lion behaviour: MR, MDB, SGD; initial data collation: MDB; data analysis: JADR, JMR; figures and tables: JADR.

\section{Conflicts of interest None.}

Ethical standards All authors have abided by the Oryx Code of Conduct for contributors. This project did not involve ethical issues with either human subjects or animals.

\section{References}

African Development Bank (2008) Pandamatenga Agricultural Infrastructure Development Project Appraisal Report. African Development Bank, Tunis Belvedere, Tunisia.

Alexandratos, N. \& Bruinsma, J. (2012) World Agriculture Towards 2030/2050. ESA Working Paper No. 12-03. Food and Agriculture Organization of the United Nations, Rome, Italy.

Azevedo, F. \& Murray, D.L. (2007) Evaluation of potential factors predisposing livestock to predation by jaguars. Journal of Wildife Management, 71, 2379-2386.

Bauer, H., Packer, C., Funston, P., Henschel, P. \& Nowell, K. (2015) Panthera leo. In The IUCN Red List of Threatened Species 2015. Http://dx.doi.org/10.2305/IUCN.UK.2016-3.RLTS.T15951A107265605.en. Butler, J.R.A. (2000) The economic costs of wildlife predation on livestock in Gokwe communal land, Zimbabwe. African Journal of Ecology, 38, 23-30. 
Carvalho, E.A.R., Zarco-González, M.M., Monroy-Vilchis, O. \& Morato, R.G. (2015) Modeling the risk of livestock depredation by jaguar along the Transamazon highway, Brazil. Basic and Applied Ecology, 16, 413-419.

Celesia, G.G., Peterson, A.T., Julian, C. \& Gnoske, T.P. (2010) Climate and landscape correlates of African lion (Panthera leo) demography. African Journal of Ecology, 48, 58-71.

Central Statistics Office of Botswana (CSOB) (2015) Poverty of Botswana. Http://botswana.opendataforafrica.org/POOB2015/ poverty-of-botswana-2015? ? village $=1003600$-pandamatenga [accessed 1 June 2016].

Clover, J. \& Eriksen, S. (2009) The effects of land tenure change on sustainability: human security and environmental change in Southern African savannas. Environmental Science \& Policy, 12, 53-70.

Dickman, A.J. (2010) Complexities of conflict: the importance of considering social factors for effectively resolving human-wildlife conflict. Animal Conservation, 13, 458-466.

Dickman, A.J. \& Hazzah, L. (2016) Money, myths and man-eaters: complexities of human-wildlife conflict. In Problematic Wildlife: a Cross-Disciplinary Approach (ed. F.M. Angelici), pp. 339-356. Springer, Cham, Switzerland.

Dickman, A.J., Hinks, A.E., Macdonald, E.A., Burnham, D. \& Macdonald, D.W. (2015) Priorities for global felid conservation. Conservation Biology, 29, 854-864.

Estes, J.A., Terborgh, J., Brashares, J.S., Power, M.E., Berger, J., Bond, W.J. et al. (2012) Trophic downgrading of Planet Earth. Science, 333, 301-306.

Harris, G., Thirgood, S., Hopcraft, J.G.C., Cromsigt, J.P.G.M. \& Berger, J. (2009) Global decline in aggregated migrations of large terrestrial mammals. Endangered Species Research, 7, 55-76.

Hayward, M.W. \& Slotow, R. (2009) Temporal partitioning of activity in large African carnivores: tests of multiple hypotheses. South African Journal of Wildlife Research, 39, 109-125.

Hemson, G. (2003) The ecology and conservation of lions: humanwildlife conflict in semi-arid Botswana. $\mathrm{PhD}$ thesis. University of Oxford, Oxford, UK.

Hemson, G., Maclennan, S., Mills, G., Johnson, P. \& Macdonald, D. (2009) Community, lions, livestock and money: a spatial and social analysis of attitudes to wildlife and the conservation value of tourism in a human-carnivore conflict in Botswana. Biological Conservation, 142, 2718-2725.

Hetem, R.S., Mitchell, D., De Witt, B.A., Fick, L.G., Meyer, L.C.R., Maloney, S.K. \& Fuller, A. (2013) Cheetah do not abandon hunts because they overheat. Biology Letters, 9, 20130472.

Inskip, C. \& Zimmermann, A. (2009) Human-felid conflict: a review of patterns and priorities worldwide. Oryx, 43, 18-34.

Kansky, R., Kidd, M. \& Knight, A.T. (2014) Meta-analysis of attitudes toward damage-causing mammalian wildlife. Conservation Biology, 28, 924-938.

KANSKY, R., KidD, M. \& KNight, A.T. (2016) A wildlife tolerance model and case study for understanding human wildlife conflicts. Biological Conservation, 201, 137-145.

Kellert, S.R., Black, M., Rush, C.R. \& Bath, A.J. (1996) Human culture and large carnivore conservation in North America. Conservation Biology, 10, 977-990.

Kgathi, D.L., Mmopelwa, G., Mashabe, B. \& Mosepele, K. (2012) Livestock predation, household adaptation and compensation policy: a case study of Shorobe village in northern Botswana. Agrekon, 51, 22-37.

Kuiper, T.R., Loveridge, A.J., Parker, D.M., Johnson, P.J., Hunt, J.E. \& Stapelkamp, B. et al. (2015) Seasonal herding practices influence predation on domestic stock by African lions along a protected area boundary. Biological Conservation, 191, 546-554.
Loveridge, A.J., Searle, A.W., Murindagomo, F. \& Macdonald, D.W. (2007) The impact of sport-hunting on the population dynamics of an African lion population in a protected area. Biological Conservation, 134, 548-558.

Loveridge, A.J., Packer, C. \& Dutton, A. (2009) Science and the recreational hunting of lions. In Recreational Hunting, Conservation and Rural Livelihoods (eds B. Dickson, J. Hutton \& W.M. Adams), pp. 108-124. Wiley-Blackwell, Oxford, UK.

Macdonald, D.W. \& Loveridge, A.J. (2010) The Biology and Conservation of Wild Felids. Oxford University Press, Oxford, UK.

Macdonald, D.W. \& Sillero-Zubiri, C. (2002) Large carnivores and conflict: lion conservation in context. In Lion Conservation Research. Workshop 2: Modelling Conflict (eds A.J. Loveridge, T. Lynam \& D.W. Macdonald), pp. 1-8. Wildlife Conservation Research Unit, Oxford University, Oxford, UK.

Madden, F. \& McQuinn, B. (2014) Conservation's blind spot: the case for conflict transformation in wildlife conservation. Biological Conservation, 178, 97-106.

Meyer, L.C.R., Fick, L., Matthee, A., Mitchell, D. \& Fuller, A. (2008) Hyperthermia in captured impala (Aepyceros melampus): a fright not flight response. Journal of Wildife Diseases, 44, 404-416.

Naidoo, R., Chase, M.J., Beytell, P., Du Preez, P., Landen, K., Stuart-Hill, G. \& Taylor, R. (2014) A newly discovered wildlife migration in Namibia and Botswana is the longest in Africa. Oryx, 50, 138-146.

NOAa (National Oceanic and Atmospheric Administration) (2016) Climate Data Online Search. Http://www.ncdc.noaa.gov/cdo-web/search [accessed 3 July 2016].

Oriol-Cotterill, A., Macdonald, D.W., Valeix, M., Ekwanga, S. \& Frank, L.G. (2015) Spatiotemporal patterns of lion space use in a human-dominated landscape. Animal Behaviour, 101, 27-39.

Packer, C., Swanson, A., Ikanda, D. \& Kushnir, H. (2011) Fear of darkness, the full moon and the nocturnal ecology of African lions. PLOS ONE, 6, e22285.

Patterson, B.D., Kasiki, S.M., Selempo, E. \& Kays, R.W. (2004) Livestock predation by lions (Panthera leo) and other carnivores on ranches neighboring Tsavo National Parks, Kenya. Biological Conservation, 119, 507-516.

Polisar, J., Maxit, I., Scognamillo, D., Farrell, L., Sunquist, M.E. \& EisenBeRG, J.F. (2003) Jaguars, pumas, their prey base, and cattle ranching: ecological interpretations of a management problem. Biological Conservation, 109, 297-310.

Pough, F.H., Janis, C.M. \& Heiser, J.B. (2012) Vertebrate Life. 9th edition. Pearson, London, UK.

R Development Core Team (2015) R: A Language and Environment for Statistical Computing. R Foundation for Statistical Computing, Vienna, Austria. Https://www.r-project.org/ [accessed 8 October 2018].

Redpath, S.M., Gutiérrez, R.J., Wood, K.A. \& YounG, J.C. (2015a) Conflicts in Conservation: Navigating towards Solutions. Cambridge University Press, Cambridge, UK.

Redpath, S.M., Bhatia, S. \& Young, J. (2015b) Tilting at wildlife: reconsidering human-wildlife conflict. Oryx, 49, 222-225.

Ripple, W.J., Estes, J.A., Beschta, R.L., Wilmers, C.C., Ritchie, E.G., Hebilewhite, M. et al. (2014) Status and ecological effects of the world's largest carnivores. Science, 343, 1241484.

Schaller, G.B. (1972) The Serengeti Lion: a Study of Predator-Prey Relations. University of Chicago Press, Chicago, USA.

Schiess-Meier, M., Ramsauer, S., Gabanapelo, T. \& König, B. (2007) Livestock predation-insights from problem animal control registers in Botswana. The Journal of Wildlife Management, $71,1267-1274$.

Soulsbury, C.D. \& White, P.C.L. (2015) Human-wildlife interactions in urban areas: a review of conflicts, benefits and opportunities. Wildlife Research, 42, 541-553. 
Stahl, P., Vandel, J.M., Herrenschmidt, V. \& Migot, P. (2001) Predation on livestock by an expanding reintroduced lynx population: long-term trend and spatial variability. Journal of Applied Ecology, 38, 674-687.

STRYKER, J.A. (2016) Thermoregulatory behaviour assessment and thermal imaging of large felids. $\mathrm{PhD}$ thesis. The University of Guelph, Guelph, Canada.

SUNQUist, M.E. \& SUNQUIST, F.C. (1989) Ecological constraints on predation by large felids. In Carnivore Behavior, Ecology, and Evolution (ed. J. Gittleman), pp. 283-301. Springer, Dordrecht, The Netherlands.

Tortato, F.R., Layme, V.M.G., Crawshaw, P.G. \& Izzo, T.J. (2015) The impact of herd composition and foraging area on livestock predation by big cats in the Pantanal of Brazil. Animal Conservation, $18,539-547$.

Treves, A., Naughton-Treves, L., Harper, E.K., Mladenoff, D.J., Rose, R.A., Sickley, T.A. \& Wydeven, A.P. (2004) Predicting human-carnivore conflict: a spatial model derived from 25 years of data on wolf predation on livestock. Conservation Biology, 18, 114-125.
USNO (United States Naval Observatory) (2016) Fraction of the Moon Illuminated. Http://aa.usno.navy.mil/data/docs/ MoonFraction.php [accessed 3 July 2016].

Valeix, M., Hemson, G., Loveridge, A.J., Mills, G. \& MACDOnALD, D.W. (2012) Behavioural adjustments of a large carnivore to access secondary prey in a human-dominated landscape. Journal of Applied Ecology, 49, 73-81.

Van Bommel, L., Bij De Vaate, M.D., De Boer, W.F. \& De Iongh, H.H. (2007) Factors affecting livestock predation by lions in Cameroon. African Journal of Ecology, 45, 490-498.

WANG, S.W. \& MACDONALD, D.W. (2006) Livestock predation by carnivores in Jigme Singye Wangchuck National Park, Bhutan, Biological Conservation, 129, 558-565.

West, P.M. \& PACKer, C. (2002) Sexual selection, temperature, and the lion's mane. Science, 297, 1339-1343.

Willmer, P., Stone, G. \& Johnston, I. (2006) Environmental Physiology of Animals. 2nd edition. Wiley-Blackwell, New Jersey, USA.

Yu, L, Endi, Z, Zhinong, L. \& Xiaojie, C. (2006) Amur tiger (Panthera tigris altaica) predation on livestock in Hunchun Nature Reserve, Jilin, China. Acta Theriologica Sinica, 26, 213-220. 